\title{
Ligand-Controlled Regiodivergence in Nickel-Catalyzed Hydroaryla- tion and Hydroalkenylation of Alkenyl Carboxylic Acids
}

\author{
Zi-Qi Li†, Yue Fu, Ruohan Deng†, Van T. Tran†, Yang Gao†, Peng Liu ${ }^{\perp *}$, and Keary M. Engle ${ }^{*}$ \\ † Department of Chemistry, Scripps Research, 10550 North Torrey Pines Road, La Jolla, California 92037, United \\ States \\ $\perp$ Department of Chemistry, University of Pittsburgh, Pittsburgh, Pennsylvania 15260, United States \\ Supporting Information Placeholder
}

\begin{abstract}
A nickel-catalyzed regiodivergent hydroarylation and hydroalkenylation of unactivated alkenyl carboxylic acids is reported, whereby the ligand environment around the metal center dictates the regiochemical outcome. Markovnikov hydrofunctionalization products are obtained under mild ligandfree conditions, with up to $99 \%$ yield and >20:1 selectivity. Alternatively, anti-Markovnikov products can be accessed with a novel 4,4-disubstituted Pyrox ligand in excellent yield and $>20$ :1 selectivity. Both electronic and steric effects on the ligand contribute to the high yield and selectivity. Mechanistic studies suggest a change in the turnover-limiting and selectivity-determining step induced by the optimal ligand. DFT calculations reveal that in the anti-Markovnikov pathway, repulsion between the ligand and the alkyl group is minimized (by virtue of it being $1^{\circ}$ versus $2^{\circ}$ ) in the rate- and regioselectivity-determining transmetalation transition state.
\end{abstract}

Catalytic, regioselective alkene functionalizations are valuable in organic synthesis owing to the widespread accessibility of alkene starting materials and the growing arsenal of transformations that have been developed.[1] In this context, systems that offer reliable and predictable access to either regioisomer from common reagents are highly desirable (Scheme 1a).[2-3] Within the expansive alkene functionalization toolkit, hydroarylation is a rapidly evolving area of synthetic methodology. [4-8] In these reactions, simple arenes (ArH) or pre-functionalized arenes (ArX or ArM) can be activated for alkene addition through a variety of mechanistic pathways to furnish the corresponding hydroarylated product.

Recently, nickel catalysis has emerged as a powerful means of effecting alkene hydroarylation.[4-5, 7] In particular, redoxneutral coupling of arylboronic acids and alkenes is attractive in that it combines programmed reactivity at the Ar-B bond with operationally simple reaction conditions and does not require stochiometric silane reductants (as in $\mathrm{R}-\mathrm{X} / \mathrm{R}_{3} \mathrm{Si}-\mathrm{H}$ systems).[5] Originally pioneered by Zhou and co-workers, such reaction systems have been largely limited to conjugated alkenes, such as styrenes and 1,3-dienes, where regioselectivity is dictated by the stability of the corresponding $\pi$-benzyl/allyl intermediate. [9] Zhao has developed a method using bidentate directing auxiliaries to enable $\gamma$-hydroarylation of non-conjugated alkenyl carbonyl compounds[10] without competitive chain-walking,[9d] though this method has disadvantages in terms of requiring directing group installation and removal steps. Hence, developing a ligand-controlled regiodivergent version of this catalytic paradigm that is compatible with nonconjugated alkenes bearing only native functionality [11] would be synthetically enabling and would complement other regioselective/divergent catalytic hydroarylation methodology involving ArH or ArX coupling partners. [4-8]

Previously, our lab has described a single example of regioswitchable hydrofunctionalization under Pd(II) catalysis,[12] where regioselectivity is hypothesized to stem from a difference in palladacycle stability with a tridentate versus bidentate directing group. In the absence of a polydentate directing auxiliary, we reasoned that regioselectivity control could alternatively arise from the combination of a weakly coordinating directing group and an appropriate ancillary ligand.

Scheme 1. Background and Synopsis of Current Work A. Regiodivergent alkene functionalization

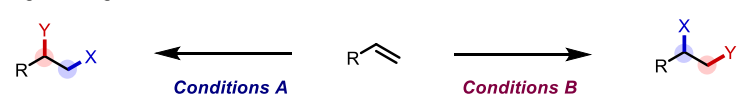

B. Previous work: Redox-neutral alkene hydroarylation under Ni catalysis

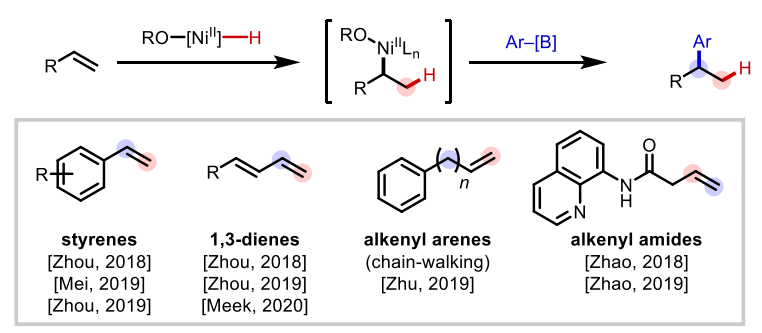

C. Directing-group-controlled regio-switchable hydrofunctionalization ${ }^{a}$

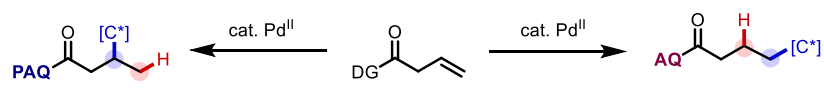

D. This work: Regiodivergent hydrofunctionalization through ligand design

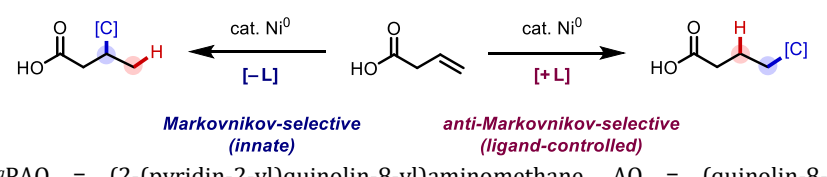

$\mathrm{PAQ}=$ (2-(pyridin-2-yl)quinolin-8-yl)aminomethane, $\mathrm{AQ}=$ (quinolin-8yl)amino, [C*]-H = 4-hydroxycoumarin.

To initiate our investigation, we selected vinyl acetic acid (1a) and $p$-tolylboronic acid as the pilot substrates. Using $\mathrm{Ni}(\mathrm{cod})_{2}$ as the pre-catalyst, $\mathrm{KO}^{t} \mathrm{Bu}$ as the base, and ${ }^{n} \mathrm{PrOH}$ as the solvent at $60^{\circ} \mathrm{C}$, we evaluated a series of different ligands with the goal of identifying conditions for both Markovnikov (M) and anti-Markovnikov (a-M) hydroarylation (Table 1). 
Interestingly, highly Markovnikov-selective hydroarylation took place under ligand-free conditions, giving $\mathbf{3 a a}$ as the major product. A control experiment ruled out an isomerization/1,4-addition sequence (vide infra); hence, we reasoned that the high selectivity could reflect the preference for forming a 5-membered metallacycle intermediate.[11] Phosphine ligands (L1-L3) gave 3aa as major product. Individually using oxazoline (L4) or pyridine(L5) ligands did not change the innate reactivity, giving 3aa in high yield and selectivity. However, bisoxazoline ligand $\mathbf{L 8}$ gave a 1:1 ratio of 2aa and 3aa.

We eventually identified Pyrox ligands as uniquely effective in favoring formation of the anti-Markovnikov hydroarylation to produce 2aa as major product. Brief optimization of the solvent and reaction temperature (see SI), led to slight improvements in yield and selectivity. We investigated the effects of steric and electronic modifications to the ligand on reactivity and selectivity. Adding steric repulsion on the pyridine ring (L9, L10) led to low yield and favored the formation of 3aa. To our delight, varying substitutions on the oxazoline ring offered a pathway towards high anti-Markovnikov-selectivity. A clear trend was observed with increased steric bulk on the 4-position, with $\mathbf{L 1 5}\left(\mathrm{R}^{1}={ }^{\mathrm{t}} \mathrm{Bu}\right)$ giving a 99\% yield and 79:21 selectivity. 4,4-Dimethyl-substituted ligand $\mathbf{L 1 7}$ gave a slightly higher selectivity of 82:18. Spirocyclic ligand $\mathbf{L 2 0}$ gave $92 \%$ yield, and increased the selectivity to 92:8.[13] The highest selectivity (95:5) with $99 \%$ yield was obtained with the previously unknown 4,4-dibenzyl-substituted ligand L19. Tuning the electronic effect on the pyridine ring using $\mathbf{L 1 5}$ as the benchmark did not achieve further improvement. A ligand containing an electron-donating group on the pyridine ring (L22) gave similar selectivity to L15. However, introduction of an electronwithdrawing substituent completely shut down the reaction. When $\mathrm{Ni}(\mathrm{cod})_{2}$ was replaced with air-stable $\mathrm{Ni}(\mathrm{cod})(\mathrm{DQ})$ and the reaction was set up outside of the glovebox, $76 \%$ yield (2aa) and 16\% yield (3aa) were obtained using $\mathbf{L 1 9}$ and no ligand, respectively (see SI for details). [14]

Table 1. Optimization of Reaction Conditions ${ }^{a}$

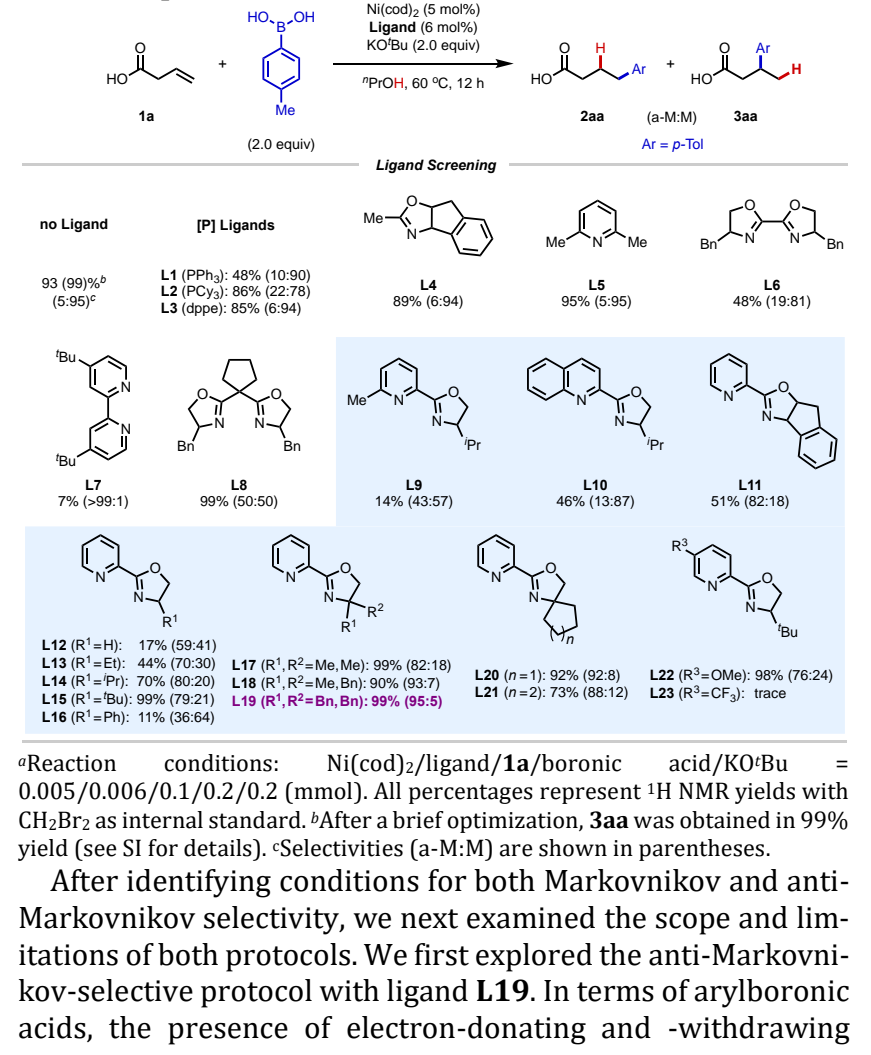

groups at the para and meta position did not affect the yield and selectivity (2aa-2ae, 2aj-2ao). Notably, potentially reactive groups, such as $-\mathrm{Cl}$ and - $\mathrm{CHO}$ (2af, 2ah), and coordinating substituents, such as -NHBoc and -CN (2ag, 2as), were also tolerated. With an electron-deficient arylboronic acid bearing 3,5-ditrifluoromethyl substituents, the reaction benefited from a less sterically hindered ligand L18, giving $\mathbf{2 a v}$ in $90 \%$ yield. ortho-Substituted arylboronic acids, which had previously proven to be recalcitrant coupling partners in related directed alkene functionalization reactions developed in our lab, can give $2 \mathbf{a z}$ in $80 \%$ yield.[11] Hydroalkenylation reactions were achieved with vinyl boronic acids, giving alkene homologation products (from $\beta-\gamma$ unsaturated alkene to $\delta$ - $\varepsilon$ unsaturated alkene) in good to excellent yields (2ba-2bd). We then evaluated a few $\alpha$-substituted 3-butenoic acid substrates. The method was found to be sensitive to steric hindrance at the $\alpha$-position. With an $\alpha$-methyl substrate, less than $10 \%$ of the product 2 ca was obtained under the standard reaction conditions, presumably due to steric clashing between the methyl group of the substrate and the bulky benzyl substituents on the oxazoline. Consistent with this hypothesis, using a less encumbered ligand, L18, in which one benzyl group is replaced with a methyl group allowed the desired product 2 ca to be obtained in $60 \%$ yield as a single regioisomer. Larger substituents on the $\alpha$ position required higher catalyst loading and even still furnished diminished yield (2cc and $2 \mathbf{c d}$ ).

Table 2. anti-Markovnikov Hydrofunctionalization Scope ${ }^{a}$

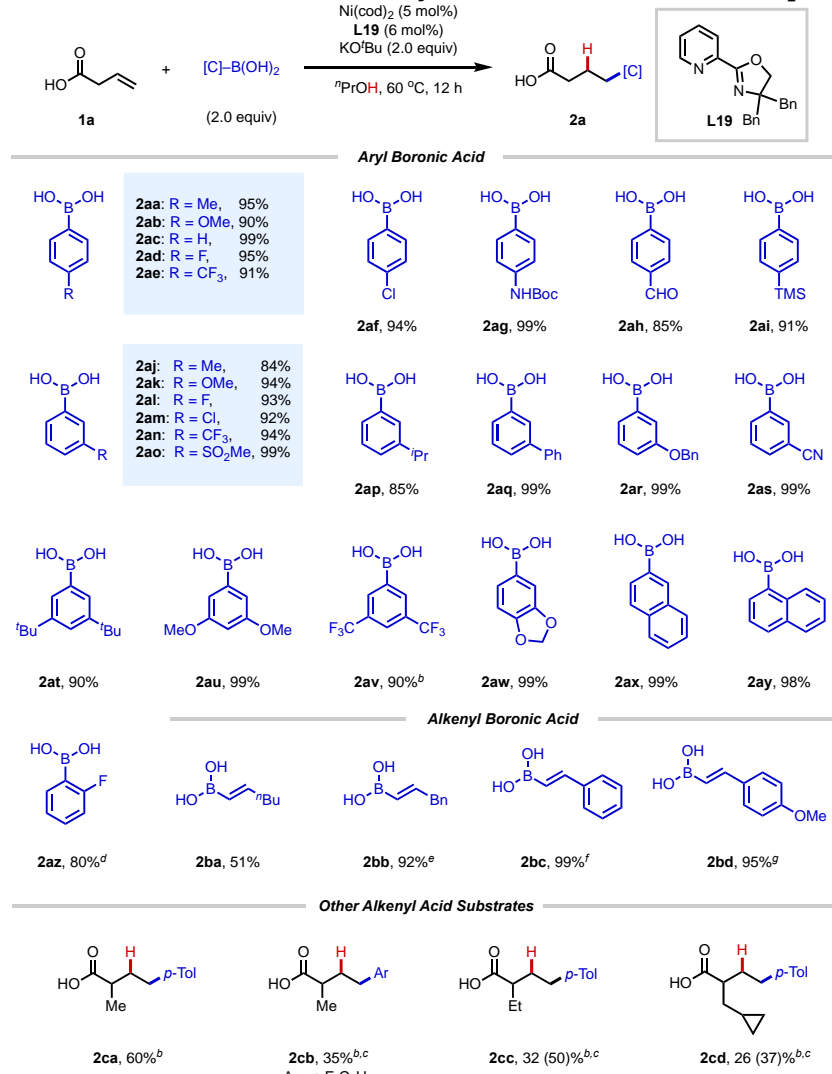

$a$ Reactions performed on $0.1 \mathrm{mmol}$ scale. Percentages represent isolated yields. Regioisomeric ratios were initially determined by ${ }^{1} \mathrm{H}$ NMR analysis of the crude reaction mixtures, and were $\geq 95: 5$ (a-M:M) in all examples tested. In a few cases, the product became enriched in the minor regioisomer during purification; in these cases, the percentages represent yields of the purified product mixture, and the product ratios are reported in the footnotes. ${ }^{b} \mathbf{L 1 8}$ was used instead of L19. ${ }^{c}$ Reactions performed on $0.2 \mathrm{mmol}$ scale with $10 \mathrm{~mol} \%$ catalyst loading. Results in parenthesis were obtained with $20 \mathrm{~mol} \%$ catalyst loading. d93:7 (a-M:M) e90:10 (a-M:M). $993: 7$ (a-M:M). $993: 7$ (a-M:M).

We next tested the scope of the Markovnikov selective hydrofunctionalization. After a brief screening (see SI for detail), 
we found that using ${ }^{n} \mathrm{BuOH}$ instead of ${ }^{n} \mathrm{PrOH}$ could provide slightly better yield and selectivity at $40{ }^{\circ} \mathrm{C}$. Similar to what we observed with the anti-Markovnikov selective hydrofunctionalizations, substituents on the para and meta position of the arylboronic acid coupling partner had little effect on the reactivity, with products (3aa-3am) obtained in good to excellent yields. Arylboronic acids containing reactive electrophilic or coordinative moieties such as $-\mathrm{Cl},-\mathrm{CHO}$ or $-\mathrm{CN}$ were incompatible. The ortho-fluoro coupling partner furnished a diminished yield of 49\% (3an) and attenuated selectivity of 17:83 (aM:M), as compared to 2az. Satisfying results were observed with alkenyl boronic acids, giving $\mathbf{3 b a}-\mathbf{3 b d}$ in good to excellent yield. With $\alpha$-substituted substrates, the Markovnikov selective products were formed in approximately $4: 1$ regioisomeric ratio and 1.7:1 dr favoring the $\mathrm{C}\left(\mathrm{sp}^{3}\right)-\mathrm{Ar}$ bond formation on the alkene face opposite to the $\alpha$-substituent (3ca-3cb). However, when sterically hindered substrate 2-(cyclopropylmethyl)but3-enoic acid was tested, the hydrogenated product was observed as major byproduct. It is worth mentioning that using 2vinyl benzoic acid as substrate gave the same product 3cd in good yield with or without ligand. Previous reports have shown that phosphine ligands or bisoxazoline ligands were required for the same type of reactivity, ${ }^{[10]}$ demonstrating the importance of the carboxylate directing group in this system.

Table 3. Markovnikov Hydrofunctionalization Scope ${ }^{a}$

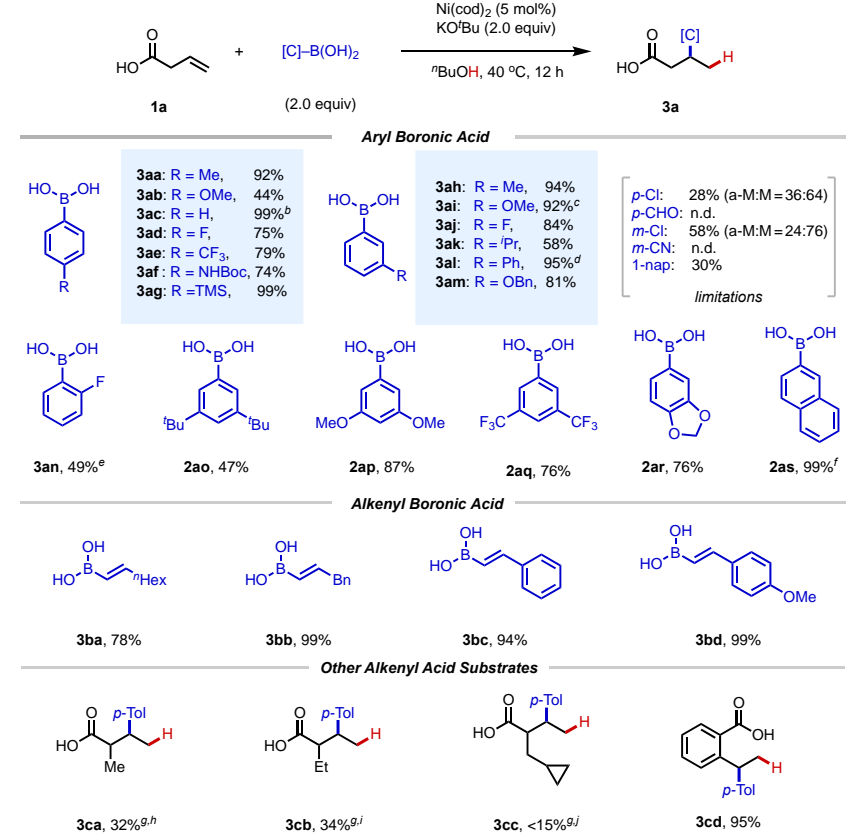

${ }^{a}$ Reactions performed on $0.1 \mathrm{mmol}$ scale. Percentages represent isolated yields unless otherwise noted. Regioisomeric ratios are $\leq 5: 95$ (a-M:M) unless otherwise noted. ${ }^{b} 7: 93$ (a-M:M). ${ }^{c 7}$ :93 (a-M:M). ${ }^{d 7: 93}$ (a-M:M). ${ }^{e} 17: 83$ (a-M:M). $f 6: 94$ (a-M:M) $g 0.2 \mathrm{mmol}$ scale, $10 \% \mathrm{Ni}(\mathrm{cod})_{2},{ }^{n} \mathrm{PrOH}, 60^{\circ} \mathrm{C}, 40$ h. ${ }^{h} \beta / \gamma(4: 1), 1.7: 1 \mathrm{dr} . i \beta / \gamma(4: 1)$, 1.7:1 dr. ${ }^{j 1} \mathrm{H}$ NMR yield with $\mathrm{CH}_{2} \mathrm{Br}_{2}$ as internal standard. Major byproduct: $57 \%$ hydrogenation of alkene.

With internal alkenes as substrates, the ligand-free conditions led to only trace product formation. With L19 as ligand, $51 \%$ mixture of $\beta$ - and $\gamma$-arylated products ( $5 \mathbf{b}$ and $\mathbf{6 b}$ ) were obtained with 2.7:1 ratio. The regioisomeric ratios are closely related to the size of distal alkyl group (see SI for detail). In these cases, both potential regioisomeric outcomes would proceed through $2^{\circ}$ alkylnickel intermediates, rather in the above cases, where there is competition between $1^{\circ}$ and $2^{\circ}$ alkylnickel formation. Hence, the results with internal alkenes suggest that while $\mathbf{L 1 9}$ enhances reactivity, it is insufficient to overcome the innate proclivity of the system to proceed via a 5 -membered metallacycle, which is why $\beta$-arylation is observed as the major product. Two other representative ligands
(L14 and L18) gave low conversion and yield. These limitations notwithstanding, the results demonstrate that through proper ligand design, we were able to achieve functionalization of these inert substrates without utilizing strong directing groups.

Table 4. Reactivity with a Representative Internal Alkene Substrate $^{a}$
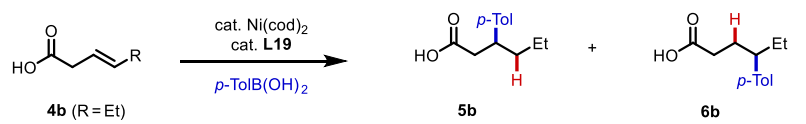

$51 \%$ yield, $5 \mathbf{b} / \mathbf{6 b}(2.7: 1)$

${ }^{a}$ Reaction performed on $0.2 \mathrm{mmol}$ scale using standard conditions from Table 1 with $20 \mathrm{~mol} \%$ catalyst loading. Percentages represent isolated yields.

3/4-Arylbutanoic acids and derivatives are of pharmacological utility.[15] To showcase the synthetic versatility of the carboxylic acid directing group, we conducted a series of diversifications on product 2ac and 3aa, which could be synthesized on large scale with excellent yield (Table 5). The classical $2 \mathrm{e}^{-}$ logic could easily transform the products into ester, alcohol, amine etc.[11] Additionally, the 1e- synthetic logic offered us a more divergent space to exert.[16] Decarboxylative borylation gave $\mathbf{7 a}$ and $\mathbf{7 d}$ in moderate yield, introducing the functional handle for future manipulation. Decarboxylative Giese reaction enabled a formal distal $(\delta$ or $\varepsilon$ ) functionalization of carbonyl compounds, giving the double homologation products $\mathbf{7 b}$ and 7e. Finally, decarboxylative cross-coupling with aryl boronic acids gave rise to the 1,2- or 1,3-diarylpropane motifs.

Table 5. Large-Scale and Derivatization Experiments ${ }^{a}$

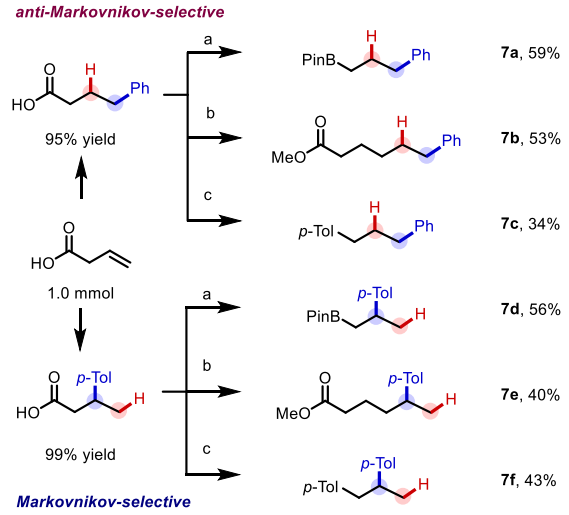

a) (i) NHPI, DIC, $10 \mathrm{~mol} \%$ DMAP, DCM, $25 \stackrel{\circ}{\circ} \mathrm{C}$; (ii) $30 \mathrm{~mol} \% \mathrm{Cu}(\mathrm{acac})_{2}, \mathrm{~B}_{2} \mathrm{Pin}_{2}$ LiOH, $\mathrm{MgCl}_{2}$, 1,4-dioxane/DMF, $25^{\circ} \mathrm{C}$. b) (i) NHPI, DIC, 10 mol\% DMAP, DCM, 25 ${ }^{\circ} \mathrm{C}$; (ii) $20 \mathrm{~mol} \% \mathrm{Ni}\left(\mathrm{ClO}_{4}\right)_{2} \cdot 6 \mathrm{H}_{2} \mathrm{O}, \mathrm{Zn}, \mathrm{LiCl}$, methyl acrylate, $\mathrm{MeCN}, 25^{\circ} \mathrm{C}$. c) (i) TCNHPI, DIC, $10 \mathrm{~mol} \%$ DMAP, DCM, $25^{\circ} \mathrm{C}$; (ii) $20 \mathrm{~mol} \% \mathrm{NiCl}_{2} \cdot 6 \mathrm{H}_{2} \mathrm{O}, 20 \mathrm{~mol} \%$ 4,4'di-tert-butyl-2,2'-bipyridine, $p$-Tol-B(OH)2, Et $3 \mathrm{~N}$, 1,4-dioxane/DMF, $85{ }^{\circ} \mathrm{C}$.

The pronounced effect of $\mathbf{L 1 9}$ on regioselectivity prompted us to consider its role in the reaction mechanism. Generally, nickel(0)-catalyzed hydroarylations with arylboronic acids are proposed to proceed via hydrometalation followed by transmetalation with the arylboronic acid and reductive elimination. Hence, we reasoned that the Markovnikov versus antiMarkovnikov selectivity would likely be determined in either the Ni-H migratory insertion step or downstream steps. To shed light on this point we turned to experimental and computational techniques.

First, to evaluate the possible role of alkene isomerization in the Markovnikov-selective protocol, we tested crotonic acid as substrate under optimized conditions, and in this case only trace amount $(<5 \%)$ of the $\beta$-arylated product 3aa was formed. This result rules out a mechanism involving isomerization followed by 1,4-addition,[17] establishing that the reaction predominantly proceeds through reaction of the $\beta, \gamma$-alkene. Next, we performed kinetic isotope effect experiments using either 
ethanol or ethanol- $\mathrm{d}_{1}$ as solvent. For the Markovnikov selective hydroarylation, we found $v_{H} / v_{D}=2.7$, suggesting that a hydride transfer process is involved in the turnover-limiting step. For the anti-Markovnikov selective reactions, a smaller ratio $\left(v_{H} / v_{D}\right.$ $=1.3$ ) was observed, suggesting that either transmetalation or reductive elimination is the turnover-limiting step, taking into consideration the possibility for a solvent kinetic isotope effect. To disambiguate between these two possibilities with L19, we examined substituent effects on initial rate with $p$-OMe and $p$ F substituted phenyl boronic acids; electron-donating substituents led to a higher initial rate, consistent with a scenario in which transmetalation is the turnover-limiting step. ${ }^{[18]}$ Deuterium labeling experiments using ethanol- $\mathrm{d}_{1}$ as solvent were conducted. In the anti-Markovnikov system, deuterium was mainly incorporated at the $\beta$-position, and in the Markovnikov system, deuterium was incorporated at the $\gamma$-position. In both cases, the presence of deuterium scrambling at the $\gamma$-position (2aa) or $\beta$-position (3aa) as well as the presence of doubly deuterated products suggests that the reaction involves a reversible hydride insertion step before the selectivity-determining step.

\section{Scheme 2. Mechanistic Experiments ${ }^{a}$}

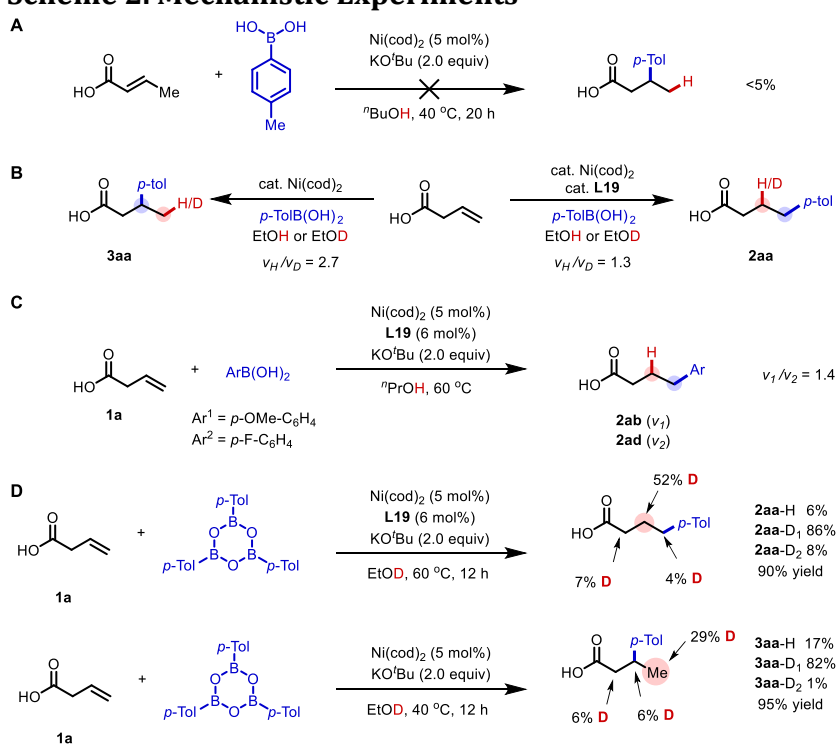

${ }^{a}$ Reactions were performed on $0.1 \mathrm{mmol}$ scale. All yields were given as ${ }^{1} \mathrm{H}$ NMR yield with $\mathrm{CH}_{2} \mathrm{Br}_{2}$ as internal standard. A) controlled experiment with crotonic acid as substrate. B) KIE study of Markovnikov and anti-Markovnikov selective hydroarylation with $p$-tol boronic acid. C) Substituent effect study by using initial rate plot of anti-Markovnikov selective hydroarylation. D) Deuterium incorporation study with ethanol- $\mathrm{d}_{1}$ as solvent.

On the basis of literature reports and the experimental mechanistic studies, three different pathways can be proposed for the hydrofunctionalization (Figure 1). A previously proposed mechanism ${ }^{[9-10] E r r o r ! ~ B o o k m a r k ~ n o t ~ d e f i n e d . ~ i n v o l v e s ~ t h e ~} \mathrm{O}-\mathrm{H}$ oxidative addition of the alcohol solvent to generate a nickelhydride intermediate, which may undergo migratory insertion followed by transmetalation (Path I) or transmetalation followed by insertion (Path II) to form an NiII(alkyl)(aryl) species and yield the hydroarylation product after reductive elimination. We surmised that an alkylnickel(II) species could be formed via an alternative pathway that involves a concerted, carboxylic acid-assisted hydronickelation of the alkene (Path III), bypassing the discrete nickel-hydride. Following transmetalation and reductive elimination as above, this path would also generate the hydroarylation product. Previous computational studies on Pd-catalyzed reactions suggest that the concerted, carboxylic acid-assisted hydropalladation[19] and $\beta$-H elimination ${ }^{[20]}$ is kinetically more favorable than alternative pathways involving palladium-hydride intermediates.
To the best of our knowledge, the analogous concerted hydronickelation pathway has not been explored computationally.

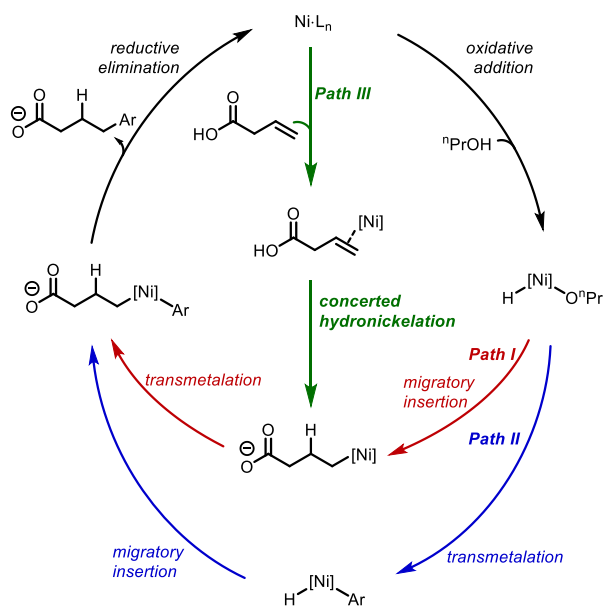

Figure 1. Possible catalytic pathways.

We performed density functional theory (DFT) calculations to study the proposed mechanisms in the hydroarylation of $\mathbf{1 a}$ and the origin of the effects of ligand $\mathbf{L 1 9}$ on the anti-Markovnikov regioselectivity (Figure 2).[21] The $\mathrm{O}-\mathrm{H}$ oxidative addition pathways using either alcohol or carboxylic acid as the hydride source both require relatively high barriers (TS3 and TS2, $\Delta \mathrm{G}^{\ddagger}$ $=36.3$ and $32.1 \mathrm{kcal} / \mathrm{mol}$, respectively). These pathways are disfavored due to the high ligand exchange energy to replace the alkene in the $\pi$-alkene complex 8 with ${ }^{n} \mathrm{PrOH}{ }^{[22]}$ and the distortion in the intramolecular carboxylic acid $\mathrm{O}-\mathrm{H}$ oxidative addition, respectively. On the other hand, the concerted hydronickelation (TS1) requires a much lower barrier (11.3 $\mathrm{kcal} / \mathrm{mol}$ with respect to 8 ) and directly leads to the primary alkylnickel(II) species 13-A. TS1 involves a fused bicyclic geometry, where the $\mathrm{O}-\mathrm{H}$ cleavage and the $\mathrm{Ni}-\mathrm{C} / \mathrm{H}-\mathrm{C}$ bond formation occur simultaneously. Although the $\mathrm{Ni}-\mathrm{H}$ distance in TS1 is relatively short (1.71 $\AA$ ), nickel-hydride species are not involved in this concerted process. These geometrical features are consistent with carboxylic acid-assisted alkene hydropalladation transition states.[19] Complex 13-A may undergo transmetalation/reductive elimination to form the anti-Markovnikov-selective hydroarylation product or isomerization to 13-M via relatively facile $\beta$-hydride elimination and alkene reinsertion (see SI for details), which would eventually lead to the Markovnikov regioisomer. Transmetalation from 13-A and 13-M occurs via four-coordinate square-planar transition states ${ }^{[23]}$ (TS4-A and TS4-M) where the pyridine group on $\mathbf{L 1 9}$ dissociates from the nickel center. ${ }^{[24]}$ Because the hydronickelation and the subsequent reductive elimination (TS5-A and TS5-M) are both facile, transmetalation is the rate- and selectivity-determining step of the catalytic cycle. The computed regioselectivity $\left(\Delta \Delta \mathrm{G}^{\ddagger}=3.1 \mathrm{kcal} / \mathrm{mol}\right)$ is consistent with the high levels of anti-Markovnikov selectivity observed in reactions with the L19-supported Ni catalyst. The regioselectivity is mainly controlled by steric repulsions between the secondary alkyl group and the benzyl groups on the oxazoline ligand that destabilize the Markovnikov-selective transmetalation transition state (TS4-M). To shed more light onto the ligand steric effects on the regioselectivity, we computed the transmetalation transition states using a sterically less demanding oxazoline ligand L10. When L10 is employed, the Markovnikov-selective transmetalation transition state is 1.1 $\mathrm{kcal} / \mathrm{mol}$ lower in energy than the anti-Markovnikov-selective isomer due to diminished steric repulsions with the ligand (see SI for detailed discussions). These results are consistent with 
the reversed regioselectivity when $\mathbf{L 1 0}$ is used in place of L19.[25]

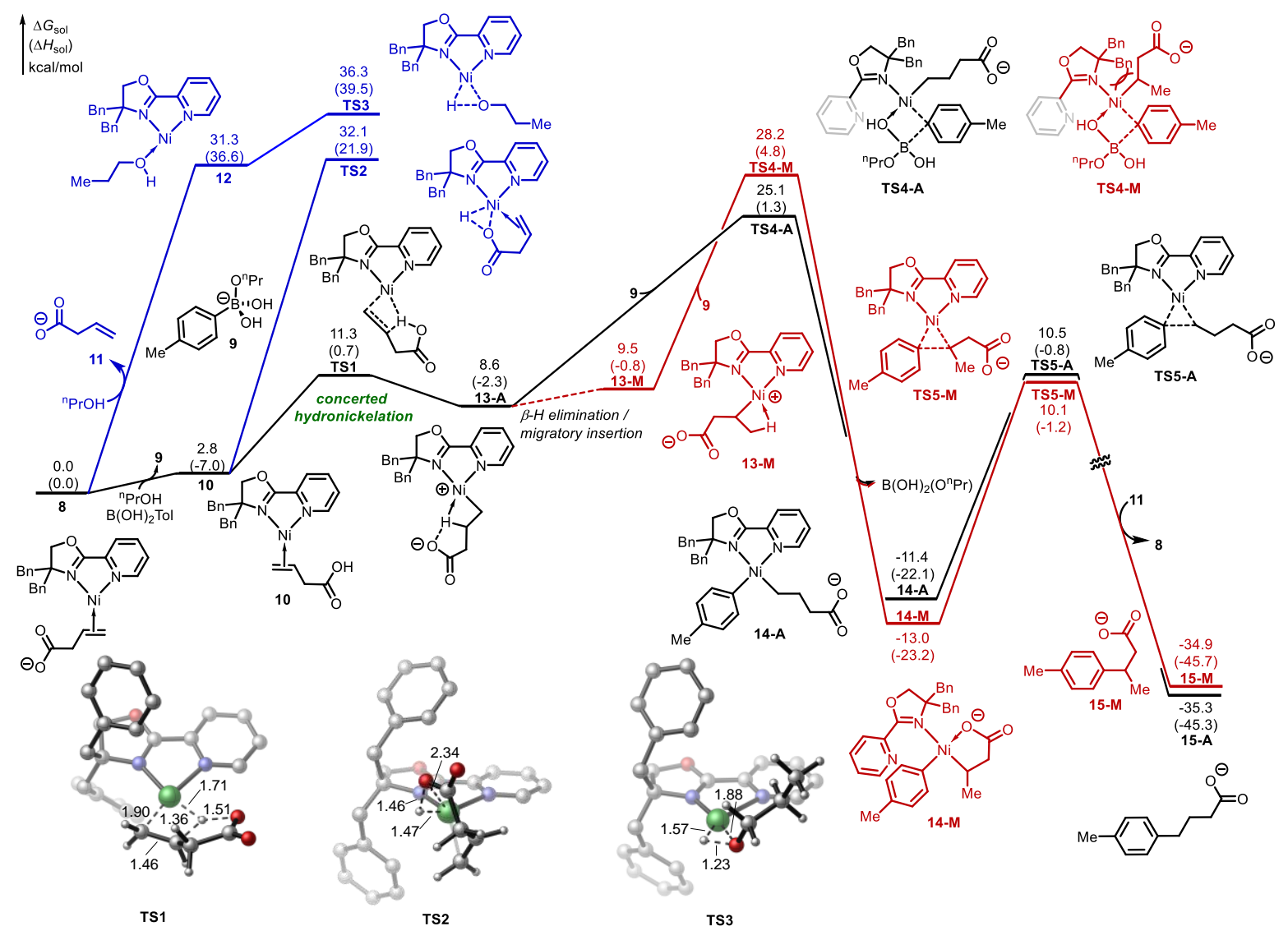

Figure 2. Computed energy profile of the hydroarylation of 1a using an L19-supported Ni catalyst. Calculations were performed at the M06/SDD-6-311+G(d,p), SMD(1-propanol)//B3LYP-D3/SDD-6-31G(d) level of theory. Bond distances are in angstroms.

In conclusion, we developed a ligand-controlled regiodivergent nickel-catalyzed hydroarylation and alkenylation reaction of alkenyl carboxylic acids. Both Markovnikov and anti-Markovnikov selective hydrocarbofunctionalized products were prepared with excellent yield and selectivity. Mechanistic studies revealed that use of the 4,4-dibenzyl Pyrox ligand leads to a switch in the turnover-limiting step and results in reversal of regioselectivity compared to ligand-free conditions. DFT calculations indicated that the anti-Markovnikov selectivity is controlled by steric repulsions between the substrate and the sterically encumbered Pyrox ligand in the transmetalation step.

\section{ASSOCIATED CONTENT}

The Supporting Information is available free of charge on the ACS Publications website.

\section{AUTHOR INFORMATION}

\section{Corresponding Author}

keary@scripps.edu

pengliu@pitt.edu
Notes

The authors declare no competing financial interest.

\section{ACKNOWLEDGMENT}

This work was financially supported by the National Science Foundation (CHE-1800280), the National Institutes of Health (R35GM128779), the Alfred P. Sloan Fellowship program, and the Camille Dreyfus Teacher-Scholar program. DFT calculations were performed at the Center for Research Computing at the University of Pittsburgh, TACC Frontera, and the Extreme Science and Engineering Discovery Environment (XSEDE) supported by NSF.

\section{REFERENCES}

(1) For representative reviews, see: (a) Yamamoto, Y.; Radhakrishnan, U. "Palladium Catalysed Pronucleophile Addition to Unactivated Carbon-Carbon Multiple Bonds." Chem. Soc. Rev. 1999, 28, 199-207. (b) Foley, N. A.; Lee, J. P.; Ke, Z.; Gunnoe, T. B.; Cundari, T. R. "Ru(II) Catalysts Supported by Hydridotris(pyrazolyl)borate for the Hydroarylation of Olefins: Reaction Scope, Mechanistic Studies, and Guides for the Development of Improved Catalysts." Acc. Chem. Res. 2009, 42, 585597. (c) McDonald, R. I.; Liu, G.; Stahl, S. S. "Palladium(II)Catalyzed Alkene Functionalization via Nucleopalladation: Stereochemical Pathways and Enantioselective Catalytic Applications." Chem. Rev. 2011, 111, 2981-3019. (d) Huang, L.; Arndt, 
M.; Gooßen, K.; Heydt, H.; Gooßen, L. J. "Late Transition MetalCatalyzed Hydroamination and Hydroamidation." Chem. Rev. 2015, 115, 2596-2697. (e) Derosa, J.; Apolinar, O.; Kang, T.; Tran, V. T.; Engle, K. M. "Recent Developments in Nickel-Catalyzed Intermolecular Dicarbofunctionalization of Alkenes," Chem. Sci. 2020, 11, 4287-4296.

(2) For a review, see: Nájera, C.; Beletskaya, I. P.; Yus, M. "MetalCatalyzed Regiodivergent Organic Reactions." Chem. Soc. Rev. 2019, 48, 4515-4618.

(3) For prominent examples involving $\mathrm{C}-\mathrm{C}$ bond formation: (a) Su, W.; Gong, T.-J.; Lu, X.; Xu, M.-Y.; Yu, C.-G.; Xu, Z.-Y. Yu, H.-Z.; Xiao, B.; Fu, Y. "Ligand-Controlled Regiodivergent Copper-Catalyzed Alkylboration of Alkenes." Angew. Chem. Int. Ed. 2015, 54, 12957-12961. (b) Xu, Z.-Y.; Jiang, Y.-Y.; Su, W.; Yu, H.-Z.; Fu, Y. "Mechanism of Ligand-Controlled Regioselectivity-Switchable Copper-Catalyzed Alkylboration of Alkenes." Chem. Eur. J. 2016, 22, 14611-14617. (c) Xu, T.; Sha, F.; Alper, H. "Highly Ligand-Controlled Regioselective Pd-Catalyzed Aminocarbonylation of Styrenes with Aminophenols." J. Am. Chem. Soc. 2016, 138, 6629-6635. (d) Zell, D.; Bursch, M.; Müller, V.; Grimme, S.; Ackermann, L. "Full Selectivity Control in Cobalt(III)-Catalyzed $\mathrm{C}-\mathrm{H}$ Alkylations by Switching of the $\mathrm{C}-\mathrm{H}$ Activation Mechanism." Angew. Chem. Int. Ed. 2017, 56, 10378-10382. (e) Meng, Q.-Y.; Wang, S.; Huff, G. S.; König, B. "Ligand-Controlled Regioselective Hydrocarboxylation of Styrenes with $\mathrm{CO}_{2}$ by Combining Visible Light and Nickel Catalysis." J. Am. Chem. Soc. 2018, 140, 3198-3201. (f) Qian, D.; Hu, X. "Ligand-Controlled Regiodivergent Hydroalkylation of Pyrrolines." Angew. Chem. Int. Ed. 2019, 58, 18519-18523. For representative examples involving C-heteroatom bond formation: (g) Sakae, R.; Hirano, K.; Miura, M. "Ligand-Controlled Regiodivergent $\mathrm{Cu}$-Catalyzed Aminoboration of Unactivated Terminal Alkenes." J. Am. Chem. Soc. 2015, 137, 6460-6463. (h) Kennemur, J. L.; Kortman, G. D.; Hull, K. L. "Rhodium-Catalyzed Regiodivergent Hydrothiolation of Allyl Amines and Imines." J. Am. Chem. Soc. 2016, 138, 11914-11919.

(4) For reviews on Ar-H/olefin coupling, see: Kakiuchi, F.; Murai, S. "Catalytic C-H/Olefin Coupling." Acc. Chem. Res. 2002, 35, 826-834. (b) Yang, L.; Huang, H. "Transition-Metal-Catalyzed Direct Addition of Unactivated C-H Bonds to Polar Unsaturated Bonds." Chem. Rev. 2015, 115, 3468-3517. (c) Crisenza, G. E. M.; Bower, J. "Branch Selective Murai-Type Alkene Hydroarylation Reactions." Chem. Lett. 2016, 45, 2-9. (d) Dong, Z.; Ren, Z.; Thompson, S. J.; Xu, Y.; Dong, G. "Transition-Metal-Catalyzed C-H Alkylation Using Alkenes." Chem. Rev. 2017, 117, 9333-9403. For recent examples, see: (g) Crisenza, G. E. M.; McCreanor, N. G.; Bower, J. F. "Branch-Selective, Iridium-Catalyzed Hydroarylation of Monosubstituted Alkenes via a Cooperative Destabilization Strategy." J. Am. Chem. Soc. 2014, 136, 10258-10261. (h) Saper, N. I.; Ohgi, A.; Small. D. W.; Semba, K.; Nakao, Y.; Hartwig, J. F. "Nickel-Catalysed anti-Markovnikov Hydroarylation of Unactivated Alkenes with Unactivated Arenes Facilitated by Non-Covalent Interactions." Nat. Chem. 2020, 12, 267-283.

(5) For recent examples of reductive hydroarylation and -alkylation, see: (a) Lu, X.; Xiao, B.; Zhang, Z.; Gong, T.; Su, W.; Yi, J.; Fu, Y.; Liu, L. "Practical Carbon-Carbon Bond Formation from Olefins through Nickel-catalyzed Reductive Olefin Hydrocarbonation." Nat. Commun. 2016, 7, 11129. (b) Friis, S. D.; Pirnot, M. T.; Buchwald, S. L. "Asymmetric Hydroarylation of Vinylarenes Using a Synergistic Combination of $\mathrm{CuH}$ and $\mathrm{Pd} \mathrm{Ca-}$ talysis." J. Am. Chem. Soc. 2016, 138, 8372-8375. (c) Friis, S. D.; Pirnot, M. T.; Dupuis, L, N.; Buchwald, S. L. "A Dual Palladium and Copper Hydride Catalyzed Approach for Alkyl-Aryl CrossCoupling of Aryl Halides and Olefins." Angew. Chem. Int. Ed. 2017, 56, 7242-7246. (d) He, Y.; Cai, Y.; Zhu, S. "Mild and Regioselective Benzylic C-H Functionalization: Ni-Catalyzed
Reductive Arylation of Remote and Proximal Olefins." J. Am. Chem. Soc. 2017, 139, 1061-1064. (e) Wang, Z.; Yin, H.; Fu, G. C. "Catalytic Enantioconvergent Coupling of Secondary and Tertiary Electrophiles with Olefins." Nature 2018, 563, 379-383. (f) Nguyen, J.; Chong, A.; Lalic, G. "Nickel-Catalyzed anti-Markovnikov Hydroarylation of Alkenes." Chem. Sci. 2019, 10, 3231-3236. (g) Bera, S.; Hu, X. "Nickel-Catalyzed Regioselective Hydroalkylation and Hydroarylation of Alkenyl Boronic Esters." Angew. Chem. Int. Ed. 2019, 58, 13854-13859.

(6) For recent examples of reductive Heck coupling, see: (a) Gurak, J. A., Jr.; Engle, K. M. "Practical Intermolecular Hydroarylation of Diverse Alkenes via Reductive Heck Coupling," ACS Catal. 2018, 8, 8987-8992. (b) Oxtoby, L. J.; Li, Z.-Q.; Tran, V. T.; Erbay, T. G.; Deng, R.; Liu, P.; Engle, K. M. "A Transient Directing Group Strategy Enables Enantioselective Reductive Heck Hydroarylation of Alkenes." Angew. Chem. Int. Ed. 2020, 59, 8885-8890. (c) Wang, C.; Xiao, G.; Guo, T.; Ding, Y.; Wu, X.; Loh, T.-P. "Palladium-Catalyzed Regiocontrollable Reductive Heck Reaction of Unactivated Aliphatic Alkenes." J. Am. Chem. Soc. 2018, 140, 9332-9336. (d) Vasquez, A. M.; Gurak, J. A., Jr.; Joe, C. L.; Cherney, E. C.; Engle, K. M. "Catalytic $\alpha$-Hydroarylation of Acrylates and Acrylamides via an Interrupted Hydrodehalogenation Reaction." J. Am. Chem. Soc. 2020, 142, 10477-10484. (7) For recent examples involving dual catalytic processes involving hydrogen-atom-transfer, see: (a) Green, S. A.; Matos, J. L. M.; Yagi, A.; Shenvi, R. A. "Branch-Selective Hydroarylation: Iodoarene-Olefin Cross Coupling." J. Am. Chem. Soc. 2016, 138, 12779-12782. (b) Green, S. A.; Vásquez-Céspedes, S.; Shenvi, R. A. "Iron-Nickel Dual-Catalysis: A New Engine for Olefin Functionalization and the Formation of Quaternary Centers." J. Am. Chem. Soc. 2018, 140, 11317-11324. (c) Shevick, S. L.; Obradors, C.; Shenvi, R. A. "Mechanistic Interrogation of Co/Ni-Dual Catalyzed Hydroarylation.” J. Am. Chem. Soc. 2018, 140, 12056-12068.

(8) Liu, T.; Yang, Y.; Wang, C. "Manganese-Catalyzed Hydroarylation of Unactivated Alkenes." Angew. Chem. Int. Ed. 2020, DOI: $10.1002 /$ anie.202003830.

(9) (a) Xiao, L.-J.; Cheng, L.; Feng, W.-M.; Li, M.-L.; Xie, J.-H.; Zhou, Q.-L. "Nickel(0)-Catalyzed Hydroarylation of Styrenes and 1,3-Dienes with Organoboron Compounds." Angew. Chem. Int. Ed. 2018, 57, 461-464. For enantioselective variants, see: (b) Chen, Y.-G.; Shuai, B.; Xu, X.-T.; Li, Y.-Q.; Yang, Q.-L.; Qiu, H.; Zhang, K.; Fang, P.; Mei, T.-S. "Nickel-Catalyzed Enantioselective Hydroarylation and Hydroalkenylation of Styrenes." J. Am. Chem. Soc. 2019, 141, 3395-3399. (c) Lv, X.-Y.; Fan, C.; Xiao, L.J.; Xie, J.-H.; Zhou, Q.-L. "Ligand-Enabled Ni-Catalyzed Enantioselective Hydroarylation of Styrenes and 1,3-Dienes with Arylboronic Acids." CCS Chem. 2019, 1, 328-334. (d) He, Y.; Liu, C.; Yu, L.; Zhu, S. "Ligand-Enabled Nickel-Catalyzed Redox-Relay Migratory Hydroarylation of Alkenes with Arylborons." Angew. Chem. Int. Ed. 2020, 59, 9186-9191. (e) Marcum, J. S.; Taylor, T. R.; Meek, S. J. "Enantioselective Synthesis of Functionalized Arenes by Nickel-Catalyzed Site-Selective Hydroarylation of 1,3-Dienes with Aryl Boronates." Angew. Chem. Int. Ed. 2020, DOI: 10.1002/anie.202004982. (f) Xu, Z.; Tang, Y.; Sheng, C.; Zhang, H.; Gan, Y.; Ji, X.; Tian, X.; Dong, K. "Nickel-Catalyzed Regio- and Diastereoselective Hydroarylative and Hydroalkenylative Cyclization of 1,6-Dienes." Chem. Commun. 2020, DOI: 10.1039/C9CC09450D. For a review, see: (g) Xiao, L.-J.; Ye, M.C.; Zhou, Q.-L. "Nickel-Catalyzed Highly Atom-Economical C-C Coupling Reactions with $\pi$ Components." Synlett 2019, 30, 361-369.

(10) (a) Lv, H.; Xiao, L.-J.; Zhao, D.; Zhou, Q.-L. "Nickel(0)-Catalyzed Linear-Selective Hydroarylation of Unactivated Alkenes and Styrenes with Aryl Boronic Acids." Chem. Sci. 2018, 9, 6839-6843. (b) Lv, H.; Kang, H.; Zhou, B.; Xue, X.; Engle, K. M.; Zhao, D. "Nickel-Catalyzed Intermolecular Oxidative Heck 
Arylation Driven by Transfer Hydrogenation." Nat. Commun. 2019, 10, 5025.

(11) (a) Derosa, J.; Kang, T.; Tran, V. T.; Wisniewski, S. R.; Karunananda, M. K.; Jankins, T. C.; Xu, K. L; Engle, K. M. “NickelCatalyzed 1,2-Diarylation of Alkenyl Carboxylates: A Gateway to 1,2,3-Trifunctionalized Building Blocks." Angew. Chem. Int. Ed. 2020, 59, 1201-1205. (b) Derosa, J.; Kleinmans, R.; Tran, V. T.; Karunananda, M. K.; Wisniewski, S. R.; Eastgate, M. D.; Engle, K. M. "Nickel-Catalyzed 1,2-Diarylation of Simple Alkenyl Amides." J. Am. Chem. Soc. 2018, 140, 17878-17883.

(12)(a) O’Duill, M. L.; Matsuura, R.; Wang, Y.; Turnbull, J. L.; Gurak, J. A., Jr.; Gao, D.-W.; Lu, G.; Liu, P.; Engle, K. M. “Tridentate Directing Groups Stabilize 6-Membered Palladacycles in Catalytic Alkene Hydrofunctionalization." J. Am. Chem. Soc. 2017, 139, 15576-15579. (b) Yang, K.; Gurak, J. A., Jr.; Liu, Z.; Engle, K. M. "Catalytic, Regioselective Hydrocarbofunctionalization of Unactivated Alkenes with Diverse C-H Nucleophiles," J. Am. Chem. Soc. 2016, 138, 14705-14712. (c) Matsuura, R.; Jankins, T. C.; Hill, D. E.; Yang, K. S.; Gallego, G. M.; Yang, S.; He, M.; Wang, F.; Marsters, R. P.; McAlpine, I.; Engle, K. M. "Palladium(II)Catalyzed $\gamma$-Selective Hydroarylation of Alkenyl Carbonyl Compounds with Arylboronic Acids." Chem. Sci., 2018, 9, 8363-8368.

(13) Shibatomi, K.; Muto, T.; Sumikawa, Y.; Narayama, A.; Iwasa, S. "Development of a New Chiral Spiro Oxazolinylpyridine Ligand (Spymox) for Asymmetric Catalysis." Synlett 2009, 2, 241-244.

(14) Tran, V. T.; Li, Z.-Q.; Apolinar, O.; Derosa, J.; Wisniewski, S. R.; Joannou, M. V.; Eastgate, M. D.; Engle, K. M. "Ni(COD)(DQ): An Air-Stable 18-Electron Ni(0)-Olefin Precatalyst." Angew. Chem. Int. Ed. 2020, 59, 7409-7413.

(15) (a) Brown, S. P.; Dransfield, P. J.; Vimolratana, M.; Jiao, X.; Zhu, L.; Pattaropong, V.; Sun, Y.; Liu, J.; Luo, J.; Zhang, J.; Wong, S.; Zhuang, R.; Guo, Q.; Li, F.; Medina, J. C.; Swaminath, G.; Lin, D. C.-H.; Houze, J. B. "Discovery of AM-1638: A Potent and Orally Bioavailable GPR40/FFA1 Full Agonist." ACS Med. Chem. Lett. 2012, 3, 726-730. (b) Rapp, M.; Giraud, I.; Maurizis, J.-C.; Madelmont, J.-C. "Synthesis and Pharmacokinetic Profile of a Quaternary Ammonium Derivative of Chlorambucil, a Potential Anticancer Drug for the Chemotherapy of Chondrosarcoma." Bio. Med. Chem. 2003, 11, 5007-5012. (c) Louvel, J.; Carvalho, J. F. S.; Yu, Z.; Soethoudt, M.; Lenselink, E. B.; Klaasse, E.; Brussee, J.; Ijzerman, A, P. "Removal of Human Ether-à-go-go Related Gene (hERG) $\mathrm{K}^{+}$Channel Affinity through Rigidity: A Case of Clofilium Analogues." J. Med. Chem. 2013, 56, 9427-9440. (d) Azoulay-Ginsburg, S.; Trobiani, L.; Setini, A.; Favaloro, F. L.; Giorda, E.; Jacob, A.; Hauschner, H.; Levy, L.; Cestra, G.; De Jaco, A.; Gruzman, A. "A Lipophilic 4-Phenylbutyric Acid Derivative that Prevents Aggregation and Retention of Misfolded Proteins." Chem. Eur. J. 2020, 26, 1834-1845.

(16) (a) Wang, J.; Shang, M.; Lundberg, H.; Feu, K. S.; Hecker, S. J.; Qin, T.; Blackmond, D. G.; Baran, P. S. "Cu-Catalyzed Decarboxylative Borylation.” ACS Catal. 2018, 8, 9537-9542. (b) Wang, J.; Qin, T.; Chen, T.-G.; Wimmer, L.; Edwards, J. T.; Cornella, J.; Vokits, B.; Shaw, S. A.; Baran, P. S. "Nickel-Catalyzed Cross-Coupling of Redox-Active Esters with Boronic Acids." Angew. Chem. Int. Ed. 2016, 55, 9676-9679. (c) Qin, T.; Malins, L. R.; Edwards, J. T.; Merchant, R. R.; Novak, A. J. E.; Zhong, J. Z.;
Mills, R. B.; Yan, M.; Yuan, C.; Eastgate, M. D.; Baran, P. S. "Nickel-Catalyzed Barton Decarboxylation and Giese Reactions: A Practical Take on Classic Transforms." Angew. Chem. Int. Ed. 2017, 56, 260-265.

(17) Hayashi, T.; Yamasaki, K. "Rhodium-Catalyzed Asymmetric 1,4-Addition and Its Related Asymmetric Reactions." Chem. Rev. 2003, 103, 8, 2829-2844.

(18) (a) Jin L.; Xin, J.; Huang Z.; He, J.; Lei, A. “Transmetalation is the Rate-Limiting Step: Quantitative Kinetic Investigation of Nickel-Catalyzed Oxidative Coupling of Arylzinc Reagents." J. Am. Chem. Soc. 2010, 132, 9607-9609. (b) Denmark, S. E.; Smith, R. C.; Chang, W.-T. T. "Probing the Electronic Demands of Transmetalation in the Palladium-Catalyzed Cross-coupling of Arylsilanolates." Tetrahedron 2011, 67, 4391-4396.

(19) (a) Mekareeya, A.; Walker, P. R.; Couce-Rios, A.; Campbell, C. D.; Steven, A.; Paton, R. S.; Anderson, E. A. "Mechanistic Insight into Palladium-Catalyzed Cycloisomerization: A Combined Experimental and Theoretical Study." J. Am. Chem. Soc. 2017, 139, 10104-10114. (b) Zhu, C.; Yang, B.; Mai, B. K.; Palazzotto, S.; Qiu, Y.; Gudmundsson, A.; Ricke, A.; Himo, F.; Bäckvall, J.-E. "Highly Selective Palladium-Catalyzed Hydroborylative Carbocyclization of Bisallenes to Seven-Membered Rings." J. Am. Chem. Soc. 2018, 140, 14324-14333.

(20) Gabr, R. K.; Hatakeyama, T.; Takenaka, K.; Takizawa, S.; Okada, Y.; Nakamura, M.; Sasai, H. "DFT Study of a 5-endo-trigType Cyclization of 3-Alkenoic Acids by Using Pd-Spirobis(isoxazoline) as Catalyst: Importance of the Rigid Spiro Framework for Both Selectivity and Reactivity." Chem. Eur. J. 2013, 19, 9518-9525.

(21) DFT calculations were performed at the M06/SDD-6311+G(d,p), SMD(1-propanol)//B3LYP-D3/SDD-6-31G(d) level of theory. See the Supporting Information for computational details.

(22) (a) Weiss, C. J.; Das, P.; Miller, D. L.; Helm, M. L.; Appel, A. M. "Catalytic Oxidation of Alcohol via Nickel Phosphine Complexes with Pendant Amines." ACS Catal. 2014, 4, 2951-2958. (b) Künzi, S. A.; Gershoni-Poranne, R.; Chen, P. "Mechanistic Studies on the Nickel-Catalyzed Cyclopropanation with Lithiomethyltrimethylammonium Triflate." Organometallics 2019, 38, 1928-1938.

(23) (a) Zhang, S.-Q.; Taylor, B. L. H.; Ji, C.-L.; Gao, Y.; Harris, M. R.; Hanna, L. E.; Jarvo, E. R.; Houk, K. N.; Hong, X. "Mechanism and Origins of Ligand-Controlled Stereoselectivity of Ni-Catalyzed Suzuki-Miyaura Coupling with Benzylic Esters: A Computational Study." J. Am. Chem. Soc. 2017, 139, 12994-13005. (b) Zhang, C.; Zhao, R.; Dagnaw, W. M.; Liu, Z.; Lu, Y.; Wang, Z.$\mathrm{X}$. "Density Functional Theory Mechanistic Insight into the Base-Free Nickel-Catalyzed Suzuki-Miyaura Cross-Coupling of Acid Fluoride: Concerted versus Stepwise Transmetalation." J. Org. Chem. 2019, 84, 13983-13991.

(24) Payard, P.-A.; Perego, L. A.; Ciofini, I.; Grimaud, L. "Taming Nickel-Catalyzed Suzuki-Miyaura Coupling: A Mechanistic Focus on Boron-to-Nickel Transmetalation." ACS Catal. 2018, 8, 4812-4823.

(25) Due to the uncertainty regarding the actual ancillary ligand(s) under the "ligand-free" conditions, we did not computationally model the Markovnikov-selective hydroarylation in the absence of Pyrox ligand. 
Insert Table of Contents artwork here

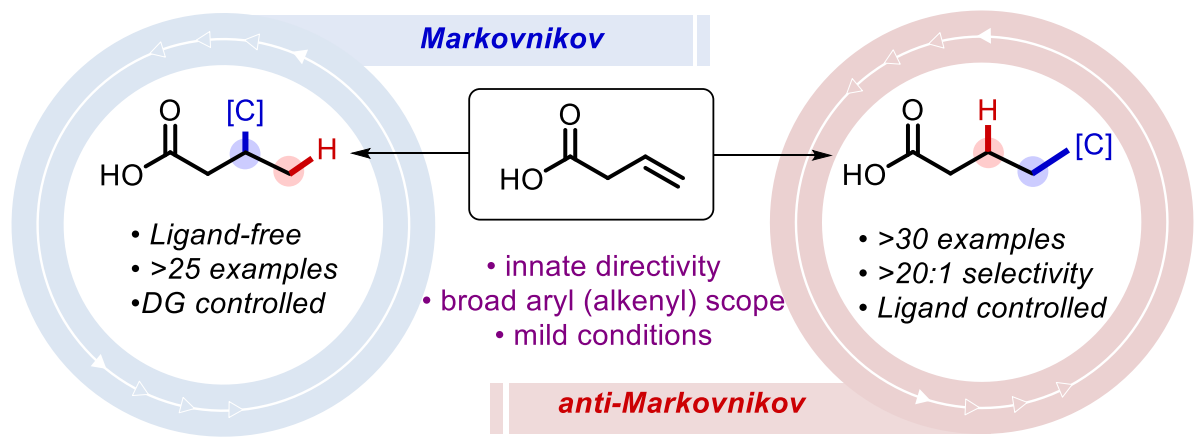

